J. Dairy Sci. 95:3593-3608

http://dx.doi.org/10.3168/jds.2011-5255

(C) American Dairy Science Association ${ }^{\circledR}, 2012$.

\title{
Novel conjugative plasmids from the natural isolate Lactococcus lactis subspecies cremoris DPC3758: A repository of genes for the potential improvement of dairy starters
}

\author{
V. Fallico,${ }^{*} \dagger$ R. P. Ross, ${ }^{\star} \ddagger$ G. F. Fitzgerald, $† \ddagger$ and O. McAuliffe ${ }^{\star 1}$ \\ ${ }^{*}$ Teagasc, Moorepark Food Research Centre, Fermoy, County Cork, Ireland \\ †Department of Microbiology, University College Cork, Ireland \\ $\ddagger$ Alimentary Pharmabiotic Centre, Cork, Ireland
}

\begin{abstract}
A collection of 17 natural lactococcal isolates from raw milk cheeses were studied in terms of their plasmid distribution, content, and diversity. All strains in the collection harbored an abundance of plasmids, including Lactococcus lactis ssp. cremoris DPC3758, whose 8-plasmid complement was selected for sequencing. The complete sequences of pAF22 $(22,388 \mathrm{~kb})$, pAF14 (14,419 kb), pAF12 (12,067 kb), pAF07 (7,435 kb), and pAF04 $(3,801 \mathrm{~kb})$ were obtained, whereas gene functions of technological interest were mapped to pAF65 (65 kb) and pAF45 (45 kb) by PCR. The plasmids of $L$. lactis DPC3758 were found to encode many genes with the potential to improve the technological properties of dairy starters. These included 3 anti-phage restriction/modification $(\mathrm{R} / \mathrm{M})$ systems (1 of type I and 2 of type II) and genes for immunity/resistance to nisin, lacticin 481, cadmium, and copper. Regions encoding conjugative/mobilization functions were present in 6 of the 8 plasmids, including those containing the $\mathrm{R} / \mathrm{M}$ systems, thus enabling the food-grade transfer of these mechanisms to industrial strains. Using cadmium selection, the sequential stacking of the $\mathrm{R} / \mathrm{M}$ plasmids into a plasmid-free host provided the recipient with increased protection against 936- and c2-type phages. The association of food-grade selectable markers and mobilization functions on L. lactis DPC3758 plasmids will facilitate their exploitation to obtain industrial strains with enhanced phage protection and robustness. These natural plasmids also provide another example of the major role of plasmids in contributing to host fitness and preservation within its ecological niche.
\end{abstract}

Key words: Lactococcus lactis, conjugative plasmid, phage resistance, food-grade selectable marker

Received December 12, 2011.

Accepted March 10, 2012.

${ }^{1}$ Corresponding author: olivia.mcauliffe@teagasc.ie

\section{INTRODUCTION}

Forty years of studies on plasmid biology have widely shown the crucial contribution of these extra-chromosomal entities to the performance, fitness, and genomic evolution of Lactococcus lactis. Strains belonging to this genus have become an essential component of modern industrial starters, mostly as a result of plasmid-encoded features promoting efficient growth in milk (i.e., metabolism of lactose, milk proteins, citrate, and other complex nutrients), resistance to environmental stresses (e.g., bacteriophages, heavy metals, and temperature/ osmotic stresses), and competitive advantages (i.e., production of bacteriocins and exopolysaccharides). Plasmids encoding these phenotypes are often mobilizable, facilitating their spread among bacteria occupying the same ecological niche. This feature has greatly contributed to the genome plasticity and evolution of lactococci, enabling them to become adapted and specialized to the dairy environment (Mills et al., 2006).

In addition to being commonly found in milk, $L$. lactis strains are naturally present on plants and, thus, it is highly likely that dairy strains actually originate from plant-derived strains transferred from forage plants and meadow grasses to milk via cattle (Salama et al., 1995; Nomura et al., 2006). Compared with milkderived strains, natural lactococcal isolates are thought to possess additional capabilities that enable them to compete and survive to multiple selections deriving from the environment, farm and traditional milk processing. Dairy strains have probably lost these traits in favor of those required for adaptation to the milk environment (Salama et al., 1995; Mills et al., 2006; Nomura et al., 2006). An example is the greater tolerance of stress demonstrated by natural isolates as a result of a variety of protection mechanisms developed to resist the numerous cytotoxic compounds and organisms (antibiotics, heavy metals, bacteriocins, and bacteriophages) present in the plant and animal environments (Leelawatcharamas et al., 1997; Schirawski et al., 2002; Ballesteros et al., 2006; Nomura et al., 2006; 
Tanous et al., 2007). These phenotypes are encoded by genes often carried by plasmids, which, again, reaffirms the role played by these genetic elements in determining the uniqueness, fitness, and performance of L. lactis strains. Based on these observations, the analysis of plasmid distribution and diversity appears to be an essential tool to evaluate the genetic potential and variability in both dairy and natural lactococcal strains.

Only a relatively limited number of $L$. lactis strains belonging to the subspecies lactis and cremoris are used in modern large-scale processes due to the need to maintain consistent quality over a vast range of products manufactured worldwide. It is, thus, arguable that the intensive exploitation of these few cultures has contributed to narrow flavor diversity in dairy products and favored the emergence of host-specific lytic bacteriophages (phages; Cogan et al., 1997; Coffey and Ross, 2002; Nomura et al., 2006). A renewed interest exists, therefore, in the isolation and characterization of new strains to replace or complement the starter cultures currently used in the dairy industry. Novel genes encoding for phage-defense systems, bacteriocin production/immunity, flavor-forming abilities, and good technological properties are particularly sought. These phenotypes are often encoded on plasmids that are easily mobilizable via natural conjugation, thus enabling the use of a food-grade approach to obtain novel starter formulations with enhanced robustness and long-term efficiency or to allow the manufacture of new and safer products (Forde and Fitzgerald, 1999; Coffey and Ross, 2002; Mills et al., 2006).

We have recently focused our attention toward the isolation, identification and characterization of L. lactis strains from natural ecological niches and good-quality artisanal products, particularly cheese. Artisanal cheeses generally possess unique sensory characteristics compared with large-scale industrial products, which may attributed to the activity of the natural milk microflora, left intact by the absence of pasteurization and probably derived from the plant and animal environments (Cogan et al., 1997; Delgado and Mayo, 2004; Ballesteros et al., 2006). In this study, we describe a preliminary analysis of the plasmid complement of 17 lactococcal isolates from artisanal cheeses for traits with potential for the improvement of starter cultures, followed by the sequencing and functional analyses of the 8-plasmid complement of the isolate L. lactis ssp. cremoris DPC3758. Our results suggest a significant contribution by the plasmid pool in protecting the host from several environmental stresses by means of 3 antiphage restriction/modification $(\mathbf{R} / \mathbf{M})$ systems, and genes for resistance to bacteriocins and heavy metals. These genetic traits are located on plasmids carrying conjugative/mobilization regions, which is suggestive of a high level of genome plasticity for L. lactis DPC3758. We demonstrate that these regions are functional and allow the exploitation of these natural plasmids to obtain lactococcal strains with enhanced phage protection and robustness.

\section{MATERIALS AND METHODS}

\section{Bacterial Strains, Bacteriophages, and Media}

A collection of 17 natural lactococcal isolates was used in this study (Table 1), which were isolated during a previous screening of artisanal raw milk cheeses from around Europe (Spain, France, Italy, and Greece) with a view to identifying strains with the potential as starters for commercial dairy fermentations (Cogan et al., 1997). Bacterial strains were routinely propagated at $30^{\circ} \mathrm{C}$ in M17 medium (Oxoid Ltd., Basingstoke, Hampshire, UK) supplemented with $0.5 \%$ (wt/vol) glucose (GM17) or lactose (LM17). Solid media contained $1.0 \%$ (wt/vol) bacteriological agar (Oxoid Ltd.). Lactococcal bacteriophages (Table 1) were propagated on sensitive hosts and phage preparations were titrated at $30^{\circ} \mathrm{C}$ according to standard procedures (Terzaghi, 1988). Bacterial strains were stocked in M17 containing $40 \%$ glycerol at $-80^{\circ} \mathrm{C}$. Working cultures were stored at $4^{\circ} \mathrm{C}$ and transferred periodically.

\section{Plasmid DNA Analysis}

Plasmid DNA of the lactococcal isolates was extracted as described elsewhere (O'Sullivan and Klaenhammer, 1993) and analyzed by electrophoresis on horizontal $0.6 \%$ agarose gels in TAE buffer $(40 \mathrm{~m} M$ Tris- $\mathrm{HCl}, 20$ $\mathrm{m} M$ Acetate, and $2 \mathrm{~m} M$ EDTA, $\mathrm{pH}$ 8.0) for $4 \mathrm{~h}$ at 80 $\mathrm{V}$. The large plasmids $(65,51$, and $36 \mathrm{~kb})$ of L. lactis DRC3 (McKay and Baldwin, 1984) and the supercoiled DNA ladder (2 to $16 \mathrm{~kb}$; Invitrogen Corp., Carlsbad, CA) were used as markers of DNA molecular size.

\section{Antimicrobial Production and Cross-Sensitivity Assays}

Antimicrobial production by the lactococcal isolates was estimated by agar well diffusion assay (Ryan et al., 1996) using L. lactis ssp. cremoris HP as the indicator strain. The bacteriocin-like nature of the antimicrobials was determined by sensitivity assays to proteases (trypsin, $\alpha$-chymotrypsin, and proteinase $\mathrm{K}, 50 \mathrm{mg} / \mathrm{mL}$ each) and temperature (50, 70, 90, and $110^{\circ} \mathrm{C}$ ) as described elsewhere (Ryan et al., 1996). The anti-listerial activity of bacteriocins was tested against Listeria innocua DPC3572 in agar well diffusion assays. Cross-sensitivity of antimicrobial producers $L$. 
Table 1. Bacterial strains and lactococcal bacteriophages used in this study

\begin{tabular}{|c|c|c|}
\hline Strain or bacteriophage & Description & Source $^{1}$ or reference \\
\hline Lactococcus lactis DPC3758 & Isolated from a French raw milk cheese: contains 8 plasmids & TFRC culture collection \\
\hline L. lactis DPC3776 & Isolated from a Spanish raw milk cheese: contains 10 plasmids & TFRC culture collection \\
\hline L. lactis DPC3749 & Isolated from a Spanish raw milk cheese: contains 9 plasmids & TFRC culture collection \\
\hline L. lactis DPC3880 & Isolated from a French raw milk cheese: contains 6 plasmids & TFRC culture collection \\
\hline L. lactis DPC3694 & Isolated from a Spanish raw milk cheese: contains 6 plasmids & TFRC culture collection \\
\hline L. lactis DPC3783 & Isolated from a Italian raw milk cheese: contains 7 plasmids & TFRC culture collection \\
\hline L. lactis DPC3901 & Isolated from a Greek raw milk cheese: contains 4 plasmids & TFRC culture collection \\
\hline L. lactis DPC3780 & Isolated from a Italian raw milk cheese: contains 2 plasmids & TFRC culture collection \\
\hline L. lactis DPC3757 & Isolated from a French raw milk cheese: contains 4 plasmids & TFRC culture collection \\
\hline L. lactis DPC3778 & Isolated from a Spanish raw milk cheese: contains 10 plasmids & TFRC culture collection \\
\hline L. lactis DPC3881 & Isolated from a French raw milk cheese: contains 7 plasmids & TFRC culture collection \\
\hline L. lactis DPC3907 & Isolated from a Italian raw milk cheese: contains 2 plasmids & TFRC culture collection \\
\hline L. lactis IL1403 & $\begin{array}{l}\text { Plasmid-free derivative of } \text { L. lactis IL594; } \\
\text { representative of subspecies lactis }\end{array}$ & Chopin et al. (1984) \\
\hline L. lactis $H P$ & $\begin{array}{l}\text { Cheese starter; indicator strain; representative } \\
\text { of subspecies cremoris }\end{array}$ & TFRC culture collection \\
\hline L. lactis DRC3 & $\begin{array}{l}\text { DNA size marker strain; contains } 8 \text { plasmids }(2,3.4,4.8,5.2,35.8 \text {, } \\
51,65 \text {, and } 78 \mathrm{~kb}) \text {; representative of subspecies diacetylactis }\end{array}$ & McKay and Baldwin (1984) \\
\hline L. lactis DPC3147 & Lacticin 3147 producer & Ryan et al. (1996) \\
\hline L. lactis DPC5558 & Nisin producer & TFRC culture collection \\
\hline L. lactis DPC5552 & Lacticin 481 producer & TFRC culture collection \\
\hline L. lactis DPC938 & Lactococcins A, B, and M producer & TFRC culture collection \\
\hline Listeria innocua DPC3306 & Indicator strain & TFRC culture collection \\
\hline Pediococcus acidilactici DPC5492 & Indicator strain & TFRC culture collection \\
\hline Lactobacillus paracasei 43338 & Indicator strain & TFRC culture collection \\
\hline
\end{tabular}

${ }^{1}$ TFRC $=$ Teagasc Food Research Centre, Moorepark, Fermoy, Co. Cork, Ireland.

lactis DPC3758 and L. lactis DPC3694 versus known bacteriocin producers was determined as follows: agar plates were seeded with $200 \mu \mathrm{L}$ of L lactis DPC3758 or L. lactis DPC3694 overnight cultures, inoculated with $50 \mu \mathrm{L}$ of neutralized supernatant from $L$. lactis DPC5558 (nisin producer), L. lactis DPC5552 (lacticin 481 producer), L. lactis DPC938 (lactococcins A, B, and M producer), and L. lactis DPC3147 (lacticin 3147 producer) into preformed wells, incubated overnight at $30^{\circ} \mathrm{C}$, and then examined for zones of growth inhibition.

\section{Phage Resistance Analysis}

Rapid screening of lactococcal strains for phage resistance/sensitivity was performed by using the spot test technique (Sanders and Klaenhammer, 1983).
Briefly, GMI7 agar plates were overlaid with top lawns of soft GM17 agar $(0.7 \%$, wt/vol) containing $100 \mu \mathrm{L}$ of overnight culture, $5 \mathrm{mM} \mathrm{CaCl}$, and $0.75 \%$ (wt/vol) glycine. Lactococcal lawns were spotted with $20 \mu \mathrm{L}$ of purified phage lysates at a suitable titer $\left(10^{8}-10^{10} \mathrm{pfu} /\right.$ $\mathrm{mL}$ ), incubated overnight at $30^{\circ} \mathrm{C}$, and then examined for zones of clearance. Glycine was added during all spot and plaque assay tests to improve visualization of plaques in poor plaque-producing phages (Lillehaug, 1997). Additionally, the plasmid complement of lactococcal strains was screened for the presence of a type I $\mathrm{R} / \mathrm{M} h s d S$ gene by using a degenerate PCR approach. The amino acid sequences of $20 \mathrm{HsdS}$ subunits from lactococcal plasmids were aligned by using T-Coffee (Notredame et al., 2000). Regions of homology within the N-terminal and central conserved domains of the 
HsdS proteins were used to design the degenerate primers 5'-GGNTTYACNGAYGAYTGGTAR-3' and 5'-GCRAANCGNAGRTCNGGNAC-3' to amplify the variable region, or target recognition domain (TRD), located in the middle of these conserved domains. By using total plasmid DNA as template, PCR amplicons of ca. $640 \mathrm{bp}$ were obtained. These were purified by the QIAquick PCR Purification kit (Qiagen GmbH, Hilden, Germany) and sequenced by double strand primer extension (Beckman Coulter Genomics Inc., Brea, CA). Sequencing data were searched for regions of similarity against DNA sequences available in public databases [GenBank (http://www.ncbi.nlm.nih.gov/genbank/), EMBL (http://www.ebi.ac.uk/embl/), DDBJ (http:// www.ddbj.nig.ac.jp/), and PDB (http://www.wwpdb. org/)] by using the nucleotide Mega BLAST algorithm of the Basic Local Alignment Search Tool (BLAST; http://blast.ncbi.nlm.nih.gov/Blast.cgi; Zhang et al., 2000).

\section{Sequencing and Annotation of the Plasmid Complement of L. lactis ssp. cremoris DPC3758}

Plasmid DNA was prepared as described elsewhere (O'Sullivan and Klaenhammer, 1993). Any residual genomic DNA was removed by treatment with Plasmid-Safe ATP-Dependent DNase (Epicentre Biotechnologies, Madison, WI), which selectively hydrolyzes linear double-stranded DNA (dsDNA) to deoxynucleotides without affecting closed circular supercoiled or nicked circular dsDNA. The 8 purified plasmids were sequenced as a pool on a 454 Genome Sequencer FLX System, after preparation of a sonication library, barcoding of the library with the Roche multiplex identifier system, and emulsion PCR (emPCR) amplification (Beckman Coulter Genomics Inc.). Automatic de novo assembly of data resulted in 92 large $(>500 \mathrm{bp})$ contigs (ca. $203 \mathrm{~kb}$ ) and 115 small (<500 bp) contigs (ca. 31 $\mathrm{kb}$ ), providing a total of ca. $234 \mathrm{~kb}$ of sequence data. Gap closure was performed by PCR using primers designed with PrimerSelect v.8.0.2 (DNASTAR Inc., Madison, WI), followed by sequencing of the PCR products (Beckman Coulter Genomics Inc.). Putative open reading frames were automatically predicted and annotated using Glimmer 2.0 (Delcher et al., 1999). Annotated DNA sequences were examined manually using the Artemis viewer (Rutherford et al., 2000) and BLASTX and BLASTP analyses (Altschul et al., 1998) were used to examine intergenic regions for putative open reading frames not identified by Glimmer, to identify putative frameshifts, and to refine the start codon assignments. The InterProScan tool (http://www.ebi. ac.uk/Tools/InterProScan), the Pfam database (Finn et al., 2010), and Conserved Domain Database (CDD; Marchler-Bauer et al., 2009) were used to predict protein function. InterProScan predicts the occurrence of functional domains and motifs/signatures in a protein by combining 12 different databases and their relative protein signature recognition methods (Zdobnov and Apweiler, 2001). The complete nucleotide sequences of plasmids pAF04, pAF07, pAF12, pAF14, and pAF22 have been submitted to the EMBL/GenBank database and are available under accession numbers JQ821353, JQ821354, JQ821355, JQ821356, and JQ821357, respectively.

\section{Association of Genetic Traits to pAF65 and pAF45 of L. lactis DPC3758}

A PCR-based approach was used to associate traits of interest (phage resistance, conjugation, and stress response) with 1 of 2 of the unclosed plasmids, pAF65 (65kb) or pAF45 (45 kb). The individual plasmids were gel extracted, purified by the Geneclean II kit (Qbiogene Inc., Carlsbad, CA), and used as template DNA in PCR reactions containing primers specific for each selected genetic trait (Table 2).

\section{Functional Analysis of the Cadmium and Copper Resistance Operons of L. lactis DPC3758}

To evaluate the functionality of the cadmium resistance operon, L. lactis DPC3758 was grown at $30^{\circ} \mathrm{C}$ for $18 \mathrm{~h}$ in LM17 medium containing increasing concentrations (0 to $0.3 \mathrm{mM}$ ) of cadmium chloride $\left(\mathrm{CdCl}_{2}\right)$. Similarly, the functionality of the copper resistance operon was evaluated by growing L. lactis DPC3758 at $30^{\circ} \mathrm{C}$ for $18 \mathrm{~h}$ in LM17 medium containing increasing concentrations (0 to $6 \mathrm{mM}$ ) of cupric sulfate $\left(\mathrm{CuSO}_{4}\right)$. In both experiments, L. lactis MG1363 was used as a reference strain due to its sensitivity to cadmium and copper.

\section{Conjugative Studies and Phage Sensitivity Assays}

A conjugation study was designed using L. lactis DPC3758 (cadmium resistant, $\mathrm{Cd}^{\mathrm{R}}$; rifampicin sensitive, $\left.\operatorname{Rif}^{\mathrm{S}}\right)$, and the plasmid-free L. lactis MG1614 (cadmium sensitive, $\mathrm{Cd}^{\mathrm{S}}$; rifampicin resistant, $\mathrm{Rif}^{\mathrm{R}}$ ) as donor and recipient strains, respectively. Overnight cultures of donor and recipient strains were used to prepare $2 \%$ inoculums that were grown at $30^{\circ} \mathrm{C}$ for $4 \mathrm{~h}$. Cells from 1-mL aliquots of each culture were harvested $\left(14,000 \mathrm{rpm}, 1 \mathrm{~min}, 4^{\circ} \mathrm{C}\right)$, resuspended in $200 \mu \mathrm{L}$ of GM17, mixed in a recipient-to-donor ratio of 1:2 and then spotted onto the center of a nonselective GM17 
Table 2. Primers used in this study to map gene features of technological importance to either plasmid pAF65 or pAF45 of Lactococcus lactis DPC3758

\begin{tabular}{|c|c|c|c|}
\hline Primer $^{1}$ & Sequence $\left(5^{\prime}-3^{\prime}\right)$ & Size (bp) & Target $^{2}$ \\
\hline $\mathrm{R} / \mathrm{M}-\mathrm{I}(\mathrm{R})$ & TGCGTAAAACCTTCAACATAATCT & & \\
\hline $\operatorname{tra1}(\mathrm{F})$ & AAAAACCTTGAATAAATACCAT & 659 & tra1 \\
\hline $\operatorname{tra1}(\mathrm{R})$ & TTAAACTTACTCAAAAATCTACACA & & \\
\hline $\operatorname{tra} 3(\mathrm{~F})$ & CAAGTAGGAGATTAGGTTATAGTCGCAGTT & 292 & tra3 \\
\hline lco $(\mathrm{R})$ & ATGTAGTTTTGATGGAAGAAGGTAGTAGT & & \\
\hline $\operatorname{nsr}(\mathrm{F})$ & GCAGTATGTGCTTTATTTTTAGG & 650 & nsr \\
\hline nsr (R) & CTTAAAGCACAAAGCGGTT & & \\
\hline lc481 (F) & AGGTGACATTTTTGGCTTTCT & 544 & lc481 \\
\hline lc481 (R) & TTCTCCCTTTTTAATAATTGCTACTG & & \\
\hline
\end{tabular}

${ }^{1} \mathrm{~F}=$ forward primer; $\mathrm{R}=$ reverse primer; $\mathrm{R} / \mathrm{M}-\mathrm{I}=$ type I restriction/modification system; $\mathrm{R} / \mathrm{M}$-IIa $=$ type II restriction/modification system; tra $1=$ conjugation region tra 1 tra $3=$ conjugation region tra $3 ;$ lco $=$ copper resistance operon; $n s r=$ nisin resistance gene; lc481 $=$ lacticin 481 immunity genes.

agar plate. Donor and recipient controls were prepared in a similar manner. Following an overnight incubation at $30^{\circ} \mathrm{C}$, the mating mix was recovered from the plate, resuspended in $10 \mathrm{~mL}$ of GM17 broth containing $0.3 \mathrm{mM}$ cadmium chloride $\left(\mathrm{CdCl}_{2}\right)$ and $100 \mu \mathrm{g}$ of rifampicin $/ \mathrm{mL}$, and then incubated further overnight at $30^{\circ} \mathrm{C}$ to enrich for $\mathrm{Cd}^{\mathrm{R}} \mathrm{Rif}^{\mathrm{R}}$ transconjugants. Donor and recipient controls were recovered from the plates, resuspended in $1 \mathrm{~mL}$ of GM17 broth, and directly plated onto LIA, containing $0.3 \mathrm{mM} \mathrm{CdCl} 2,100 \mu \mathrm{g}$ of rifampicin $/ \mathrm{mL}$, and $0.004 \%$ bromocresol purple. Following overnight incubation, cells from a 1-mL aliquot of the mating mix were harvested, resuspended in $1 \mathrm{~mL}$ of GM17, and then plated onto selective media. Putative transconjugants, appearing as white colonies, were selected and the plasmid DNA profile was analyzed to verify the acquisition of the plasmids. Confirmed transconjugant strains were examined for their sensitivity to phages $\mathrm{c} 2$ and 712 by using the plaque assay technique (Terzaghi, 1988). Efficiency of plaquing (EOP) was determined by dividing the phage titer on the test strains by the titer on the homologous host L. lactis MG1614.

\section{RESULTS AND DISCUSSION}

\section{Preliminary Characterization of the Natural Lactococcal Strains}

Natural L. lactis isolates are thought to possess a broader genetic makeup compared with industrial strains, with plasmid-encoded functions generally reflecting host adaptation to different ecological niches (Mills et al., 2006). Based on this rationale, 17 natural lactococcal strains, isolated from raw milk cheeses dur- ing a previous study (Cogan et al. 1997), were characterized for the diversity and genetic content of their plasmids with the aim of identifying novel plasmid-encoded genes for the technological improvement of dairy starters. A rich and heterogeneous content of plasmids was found in all investigated strains, with each one harboring between 2 and 10 plasmids with sizes ranging from 2 to $80 \mathrm{~kb}$ (Figure 1a). This latter finding was especially intriguing, as large plasmids are expected to contain most of the genetic information providing a competitive advantage to the lactococcal host to flourish in its natural ecosystem (Siezen et al., 2005).

Several preliminary tests were undertaken to identify genetic traits of potential interest (i.e., antimicrobial production and phage resistance) on the plasmid complement of these isolates. First, the supernatant from an overnight culture of each strain was assayed for antimicrobial activity. Three strains (L. lactis DPC3758, DPC3694, and DPC3901) were found to produce narrow-spectrum antimicrobial compounds, which inhibited the growth of the indicator strain $L$. lactis HP (Figure 1b) but not the growth of indicators such as Listeria innocua, Lactobacillus paracasei, and Pediococcus acidilactici. The antimicrobials produced by L. lactis DPC3758 and DPC3694 were sensitive to proteases and thermal treatments, which is indicative of a bacteriocin-like nature, whereas the compound produced by L. lactis DPC3901 was unaffected by such treatments. Results of cross-sensitivity tests (data not shown) suggested that L. lactis DPC3758 and DPC3694 were likely to produce a lacticin 481- or a lactococcinlike protein and to harbor immunity to nisin, lacticin 481, and lactococcins A, B, and M. Despite these similarities, differences in RAPD-PCR patterns (results 

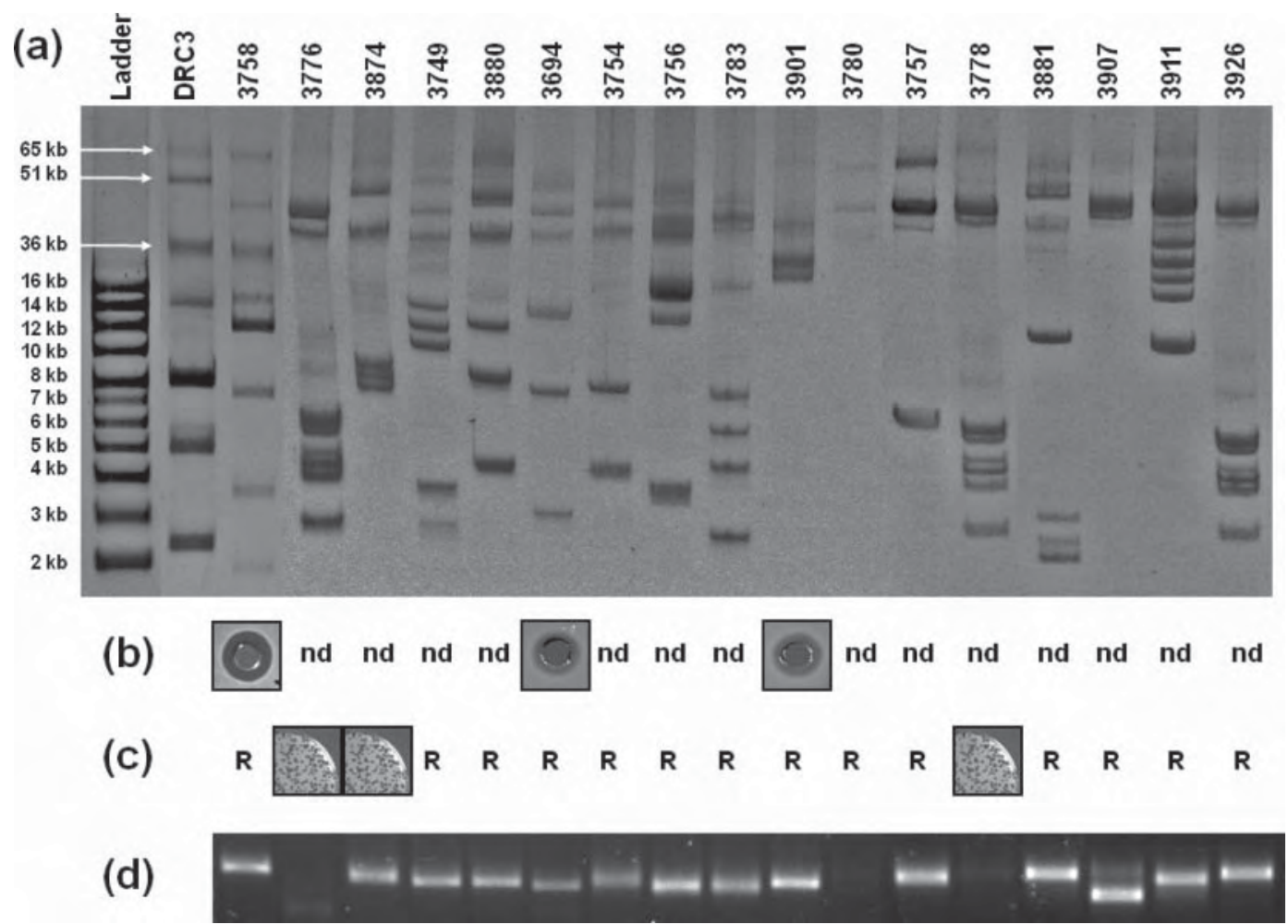

Figure 1. Preliminary characterization of the natural lactococcal isolates. (a) Distribution and diversity of the plasmid DNA complement. The plasmid profile of Lactococcus lactis DRC3 provides reference plasmids of large sizes (36, 51, and $65 \mathrm{~kb})$ as a complement to the 2- to 16-kb molecular size ladder. (b) Antimicrobial production on agar well diffusion assays by using L. lactis HP as indicator strain. Icon = positive; nd $=$ not detected. (c) Resistance/sensitivity to $\mathrm{c} 2$-type phages (c2, ml3, and eb1) by using the spot test technique. $\mathrm{R}=$ resistant; icon $=$ sensitive. (d) PCR detection of type I restriction/modification $h s d S$ subunits.

not shown), plasmid profiles, and bacteriocin potency excluded that L. lactis DPC3758 and DPC3694 are different isolates of the same strain.

Second, spot assays with several c2-type (c2, ml3, and eb1) and 936-type (sk1, 712, and hp) phages revealed that 3 isolates (L. lactis DPC3776, DPC3874, and DPC3778) were exclusively sensitive to c2-type phages, whereas the remaining strains were resistant to all phages tested (Figure 1c). In L. lactis, host protection from phage attack is often afforded by its plasmid complement via 1 or more of 4 mechanisms of resistance known to date: 1) inhibition of phage adsorption, 2) phage DNA injection blocking, 3) phage DNA R/M, and 4) abortive phage infection. Of these, $\mathrm{R} / \mathrm{M}$ systems are the most interesting, as their phage-inactivation strategy has no deleterious effects on host viability and, in the case of type I R/M, they can modulate the level of phage restriction by homologous recombination of HsdS specificity subunits (Schouler et al., 1998b; Mills et al., 2006). Consequently, we investigated our collection of natural lactococcal strains for the presence of type I R/M $h s d S$ genes by using degenerate primers designed to target the N-terminal TRD (Figure 1d).
Thirteen of the 17 isolates produced an amplicon of the expected size (ca. $640 \mathrm{bp}$ ), indicating the presence of at least $1 h s d S$ gene and, possibly, of a complete type I $\mathrm{R} / \mathrm{M}$ system in their plasmid complement.

\section{Sequence Analysis of the Plasmid Complement of L. lactis ssp. cremoris DPC3758}

These initial findings prompted a deeper investigation of the genetic properties of these natural isolates by sequencing the entire plasmid complement of $L$. lactis ssp. cremoris DPC3758. This strain was chosen, as it exhibited several technologically interesting characteristics: 1) complete resistance to c2- and 936-type phages, 2) the presence of a $h s d S$ gene and putatively of an associated type I R/M system, 3) antimicrobial production, and 4) a rich extra-chromosomal complement composed of 8 plasmids, with sizes ranging from 2 to $80 \mathrm{~kb}$. Additionally, L. lactis DPC3758 was the only strain in the investigated collection to belong to the subspecies cremoris, which is highly suitable for the manufacture of Cheddar and other cheese varieties (Salama et al., 1995; Nomura et al., 2006). 
High-throughput sequencing of L. lactis DPC3758 plasmids generated $234 \mathrm{~kb}$ of data distributed over 207 contigs. Following initial BLAST analysis and gene annotation, a PCR-mediated gap closure strategy was adopted to complete each of the plasmid sequences. This approach was successful in the case of 5 plasmids, namely pAF22, pAF14, pAF12, pAF07, and pAF04 (Figure 2; Supplementary Material Tables 1-5, available online at http://www.journalofdairyscience.org/). These plasmids displayed a GC content ranging from 32 to $36 \%$, which is consistent with the 31 to $36 \%$ range described for lactococcal plasmids (Siezen et al., 2005). However, the presence of numerous secondary structures and many homologous insertion sequences rendered the primer walking strategy unsuccessful in closing the largest plasmids, pAF65 (65 kb) and pAF45 $(45 \mathrm{~kb})$. In these cases, gap closure focused on those regions containing traits of technological interest (phage resistance systems, conjugation/mobilization regions, and stress response/selectable markers), which were then associated with either pAF65 or pAF45 using a PCR approach (Figure 2; Supplementary Material Tables 6-12, available online at http://www.journalofdairyscience.org/). The sequencing data revealed that the antimicrobial produced by L. lactis DPC3758 is a lactococcin-like bacteriocin whose genetic determinants are located on the chromosome.

\section{A Battery of 3 R/M Systems Protects L. lactis DPC3758 Against Phage Attack}

The plasmid complement of L. lactis DPC3758 harbors a significant array of defense mechanisms against phage attack, including 1 type I R/M and 2 type II $\mathrm{R} / \mathrm{M}$ systems, which confirms suggestions that the latter mechanisms are the most common in lactococci (Mruk et al., 2003). Type I R/M systems are typically made up of 3 genes ( $h s d R M S$ ), transcribed in the same direction, and coding for 3 subunits that are responsible for DNA restriction (HsdR), modification (HsdM), and specificity (HsdS), respectively (Murray, 2000). The type I R/M system (R/M-I) of L. lactis DPC3758 is located on pAF65 (Figure 2; Supplementary Material Table 7, available online at http://www.journalofdairyscience.org/). The $h s d R$ gene encodes a restriction endonuclease (REase, 995 AA) containing conserved helicase-like (COG0610) domains, whereas the 515-AAlong product of $h s d M$ is a typical $\mathrm{N}^{6}$-adenine $\beta$-class methyltransferase (MTase, pfam02384). Both proteins are $99 \%$ identical to the HsdR and HsdM enzymes encoded by homologous genes present on the chromosome of L. lactis IL1403 (Schouler et al., 1998a). In contrast, the specificity protein (428 AA) encoded by R/M-I $h s d S$ of pAF65 is $61 \%$ similar to listerial HsdS subunits and shares only $36 \%$ identity with its homolog from $L$. lactis IL1403. Low similarities among HsdS subunits is generally common and reflects the large variability existing within their TRD, which are responsible for imparting target sequence specificity to both the restriction and modification activities of the type I R/M complex (Murray, 2000). However, AA sequence alignments revealed that the HsdS of pAF65 mostly diverges from that of L. lactis IL1403 and other lactococci at the C-terminal TRD (AA positions 281-399), where the sequence identity drops to as low as $18 \%$ (Figure 3 ). Indeed, this region is $84 \%$ similar to a TRD shared by some Listeria, Enterococcus, and Lactobacillus organisms, a finding that would suggest a putative shuffling of $h s d S$ TRD. Such an event has been reported to have generated the co-integrated plasmid pAH90 from the native plasmids pAH33 and pAH82 in L. lactis DPC721 (O'Sullivan et al., 2000). In pAH90, the recombination event formed 2 novel hybrid $h s d S$ genes that had interchanged the $\mathrm{N}$ - and $\mathrm{C}$-terminal TRD of the parent subunits and sequence analysis revealed that the site of recombination involved a 19-AA sequence (KVPELRFAGFADDWEERKL) located in the conserved central domain of both HsdS proteins (O'Sullivan et al., 2000). Interestingly, this exact sequence is present at the end of the conserved central domain (AA positions 256-276) of the HsdS of L. lactis DPC3758, just preceding the C-terminal TRD and exactly marking the start of the divergence of sequence from the HsdS of L. lactis IL1403 (Figure 3). These findings support the hypothesis that a homologous recombination event may have promoted the acquisition of a novel TRD, possibly from a Listeria, Enterococcus, or Lactobacillus strain, and of a likely novel specificity in the R/M-I HsdS of L. lactis DPC3758. Such an event is highly feasible, as members of these genera usually coexist in the rich and diverse microflora typical of raw milk cheeses. O'Sullivan et al. (2000) aligned the variable regions of all known HsdS proteins of L. lactis and S. thermophilus and found evidence of putative domain-shuffling events occurring between members of these 2 genera. This led the authors to speculate that the generation of new specificities via homologous recombination is a widespread strategy used by Lactococcus to enhance its natural defenses against phages. Indeed, the formation of pAH90 occurred in a background of high-titer phage challenge for L. lactis DPC721 (O'Sullivan et al., 2000). In the case of pAF65, it is tempting to speculate that its raw milk origins would favor the establishment of a resilient microflora and, in turn, the likely emergence of a reservoir of homologous phages. Phages are able to overcome the restriction systems of the host by mutating the restriction sites in their genomes (Forde and Fitzgerald, 1999; Coffey and Ross, 2002). Conse- 


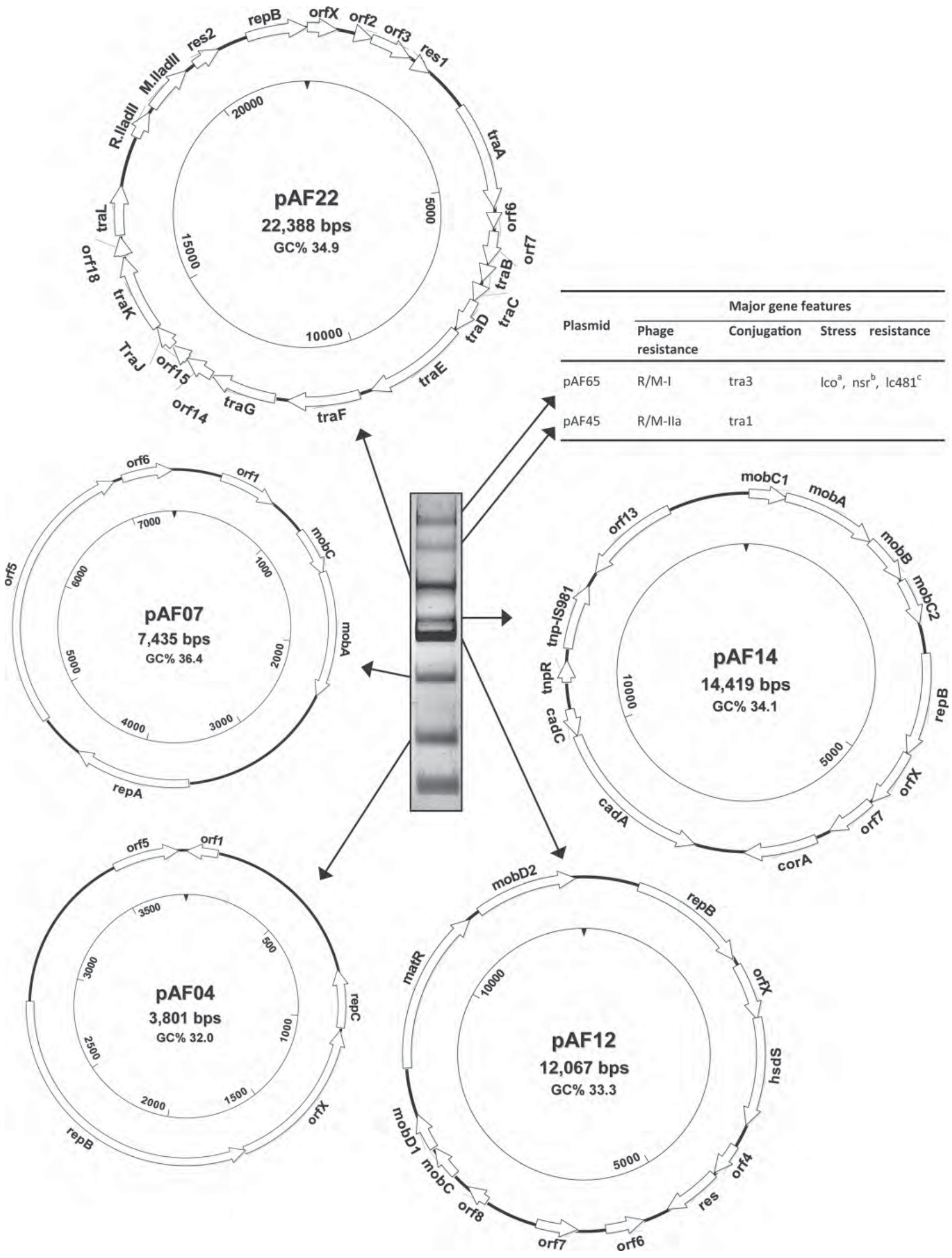

Figure 2. Physical and genetic maps of plasmids pAF22, pAF14, pAF12, pAF07, and pAF04 of Lactococcus lactis DPC3758. Position and orientation of genes are indicated by arrows. Inner circles show the nucleotide numbering. The table shows the features of technological interest mapped to plasmids pAF65 and pAF45 by PCR.

Journal of Dairy Science Vol. 95 No. 7, 2012 
quently, the acquisition of novel restriction specificities by genetic recombination may represent the evolutionary response of lactococci to the mutational capacity of phages to avoid the host anti-phage mechanisms.

In addition to R/M-I, L. lactis DPC3758 also contains the type II R/M systems R/M-IIa and R/M-IIb, located on pAF45 and pAF22 (Figure 2; Supplementary Material Tables 1 and 6, available online at http:// www.journalofdairyscience.org/), respectively. Type II R/M systems are typically composed of 2 enzymes: an REase that recognizes and cleaves a specific short DNA sequence (4-8 bp), and an MTase that modifies the same sequence to protect the host DNA against the action of the cognate restriction enzyme (Mruk et al., 2003)., The upstream gene in R/M-IIa encodes a protein of $296 \mathrm{AA}$ containing typical $\mathrm{N}^{6}$-adenine $\beta$-class MTase (pfam01555) and DNA modification methylase (COG0863) domains, whereas the downstream gene encodes a protein of 335 AA containing an HindIII restriction endonuclease domain (pfam09518). These proteins are virtually identical to the MTase (99\%) and REase (96\%) enzymes of the LlaCI system found on plasmid pAW153 from L. lactis ssp. cremoris W15 (Madsen and Josephsen, 1998a). Similar to the LlaCI system, the R/M-IIa genes of L. lactis DPC3758 are arranged in a convergent fashion and are separated by a 94-bp sequence. The second type II R/M system, R/MIIb, consists of a 180-AA REase, belonging to the Bsp6I superfamily (pfam09504), and a 317-AA cytosine-C5 specific DNA methylase (cd00315) belonging to the superfamily of $S$-adenosylmethionine-dependent MTases (cl12011). In this case, both genes are transcribed in the same direction and their gene products are virtually identical to the REase (98\%) and MTase (99\%) enzymes of the LlaDII system found on the naturally occurring 8.9-kb plasmid pHW393 in L. lactis ssp. cremoris W39 (Madsen and Josephsen, 1998b). Taken individually, these R/M-II systems have limited restriction efficiency (Madsen and Josephsen, 1998a,b). However, the most likely benefit for L. lactis DPC3758 in harboring these systems is in their cooperative activity with R/M-I, which confers the strain with wider and greater protection against different phage types. Phages attacking this strain will be sequentially challenged by 3 systems possessing different $\mathrm{R} / \mathrm{M}$ specificities; those that will be uncut or restricted with low efficiency by 1 system will still have to face 2 other systems before being able to proliferate within the cell. The additive restriction phenomenon and enhanced host protection afforded by the stacking of anti-phage mechanisms is well documented (Josephsen and Klaenhammer, 1990; Madsen and Josephsen, 1998a; O'Sullivan et al., 1998; Coffey and Ross, 2002; Mills et al., 2006). Lactococcus lactis DPC3758 may have naturally opted to stack multiple
$\mathrm{R} / \mathrm{M}$ systems to resist phage invasion as this strategy could prove crucial in providing protection against existing and forthcoming phages, thus allowing the strain to survive and become established in the challenging habitat of raw milk cheeses.

\section{The Majority of L. lactis DPC3758 Plasmids Contain Genes for Conjugative/Mobilization Functions}

Conjugative plasmids are commonly found in lactococci and play a fundamental role in their evolution as they allow the transfer of genome-size segments (Mills et al., 2006). In terms of starter improvement, this feature is extremely important as the conjugal transfer of naturally occurring plasmids is the most widely accepted approach for the genetic improvement of dairy starters designed for human consumption (Forde and Fitzgerald, 1999; Coffey and Ross, 2002; Mills et al., 2006). Six of the 8 plasmids in L. lactis DPC3758 contain genetic regions associated with predicted conjugative/mobilization functions (Figure 2; Supplementary Material Tables 1-12, available online at http://www. journalofdairyscience.org/). First, pAF45 contains a 17,264-bp conjugal transfer region (tra1; Figure 2; Supplementary Material Table 8) composed of 18 genes, which is virtually identical (99\% at DNA level, and 97 to $100 \%$ at protein level) to the tra operon of the lactococcal plasmid pMRC01 (Dougherty et al., 1998), a finding that may be indicative of a genetic exchange event between these plasmids. This region renders pMRC01 self-transmissible, a characteristic that has allowed the efficient transfer of the plasmid to more than 30 different lactococcal strains, including derivatives of commercial starters (Ryan et al., 1996; Coffey and Ross, 2002). Similarly, tra1 could mediate the transfer of pAF45 and of the associated anti-phage mechanism (R/M-IIa). A second large conjugal region, tra2, is present on pAF22, whose overall genetic makeup is completed by the $\mathrm{R} / \mathrm{M}$-IIb system, a replication region and 2 genes encoding for putative sitespecific resolvase/invertase (cd03768) enzymes (Figure 2; Supplementary Material Table 1, available online at http://www.journalofdairyscience.org/). Region tra2 consists of 10 genes ( $\operatorname{tra} A B C D E F G J K L$ ), encoding proteins with 43 to $78 \%$ similarity to homologs present on plasmids plca36 from Lactobacillus casei Zhang (Zhang et al., 2008), pLgLA39 from Lactobacillus gasseri LA39 (Ito et al., 2009), and pWCFS103 from Lactobacillus plantarum (van Kranenburg et al., 2005). The third conjugal region, tra3, of L. lactis DPC3758 is located on pAF65, also carrying the R/M-I system (Figure 2; Supplementary Material Table 9, available online at http://www.journalofdairyscience.org/). Data for 7 (traCDEFJKI) of the 12 putative genes composing 

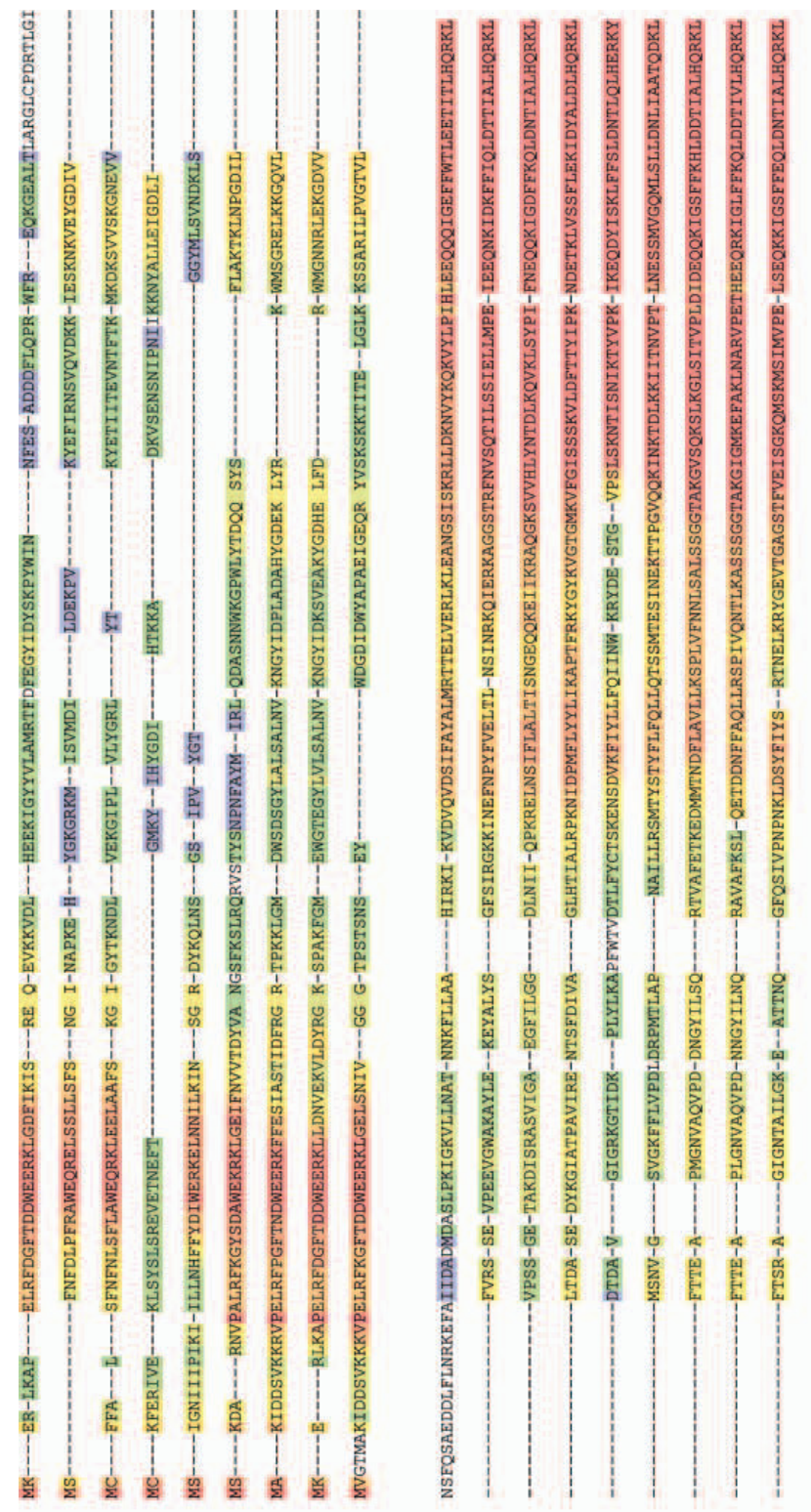

울

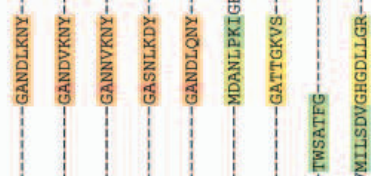

实苛圷

कृष 융

范浔

$\stackrel{0}{0}$

:

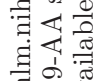

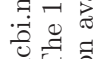

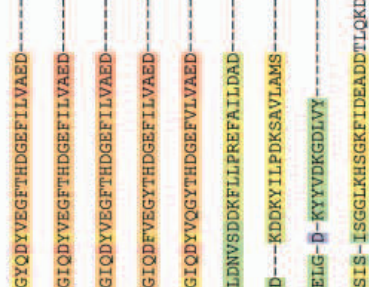

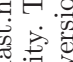

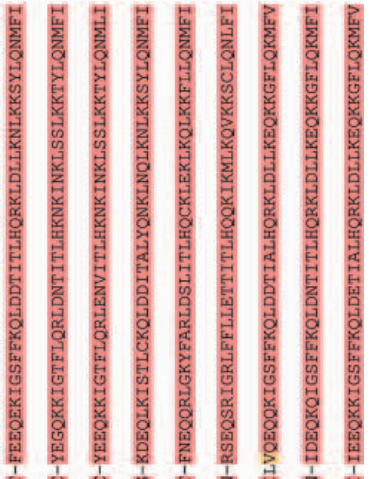

․ㅡㄹ.
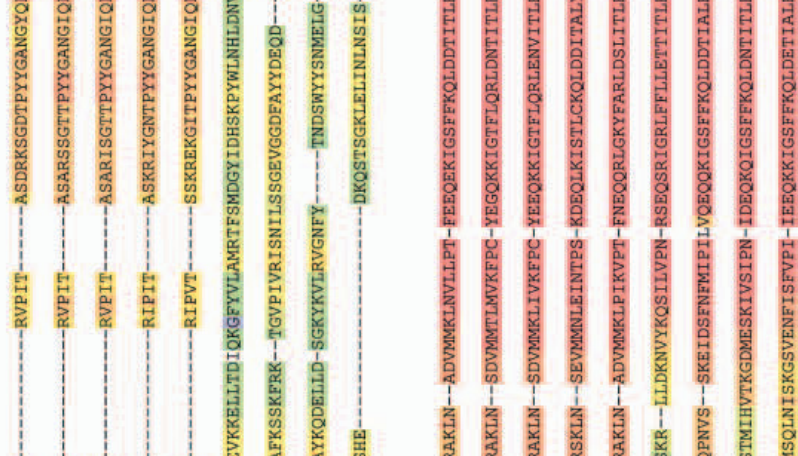

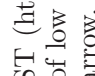

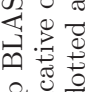

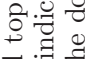

范完

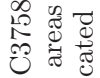

窟: 要

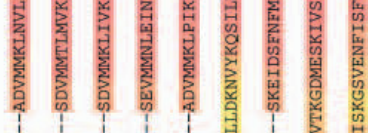

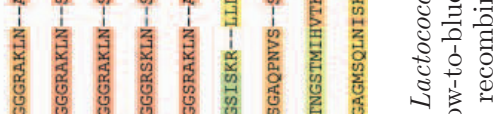

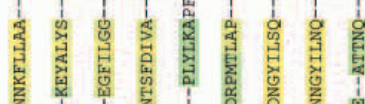

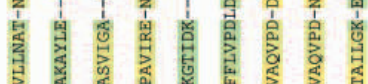

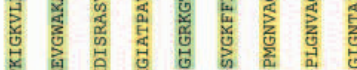

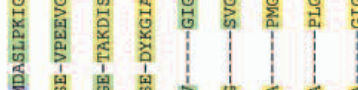

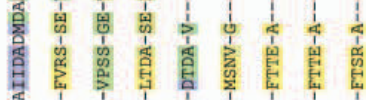
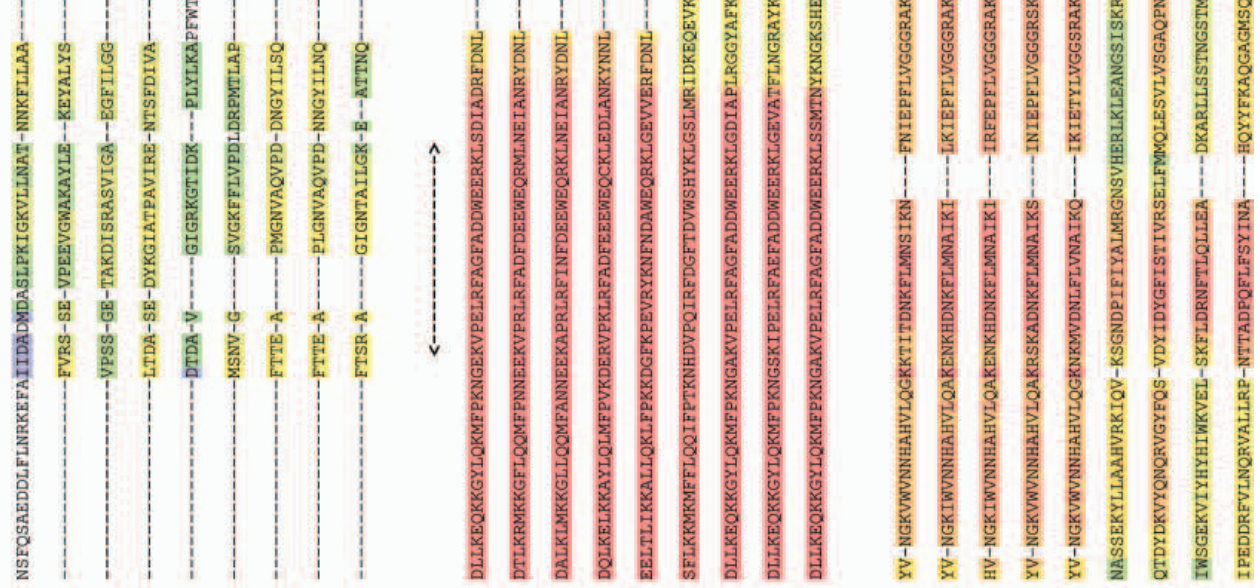

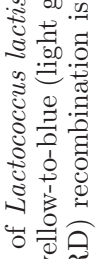

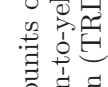

产

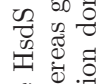

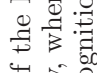

岁要

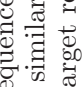

당.

类

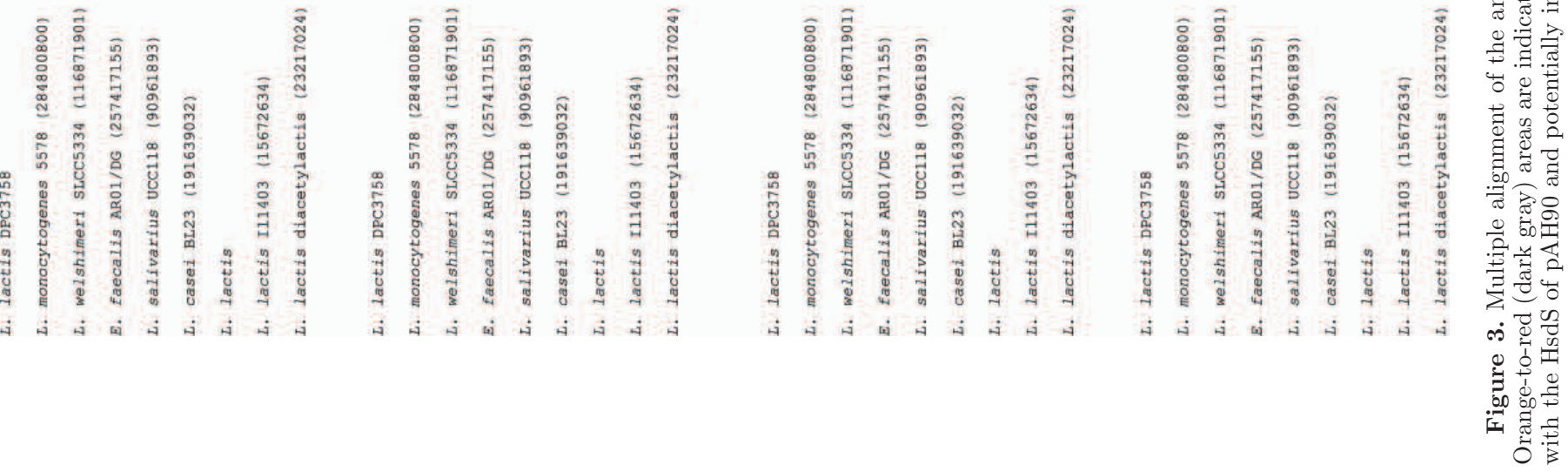


tra3 were obtained from the original sequencing, but further attempts to close gaps within this region were unsuccessful. Tra3 genes encode for products with 31 to $64 \%$ similarity mainly to conjugation proteins from Carnobacterium sp. AT\%. Homology to Tra proteins from plca36 (Zhang et al., 2008), pLgLA39 (Ito et al., 2009), pWCFS103 (van Kranenburg et al., 2005), and pMRC01 (Dougherty et al., 1998) is much lower, in the region of 30 to $40 \%$.

In addition to the conjugative abilities of pAF65, pAF45, and pAF22, a mobilization gene cluster (mob$C_{1} A B C_{2}$ ) is located on pAF14 (Figure 2; Supplementary Material Table 2, available online at http://www. journalofdairyscience.org/). This mob region is $99 \%$ identical at the nucleotide level to the corresponding region in pNZ4000 (van Kranenburg et al., 2000). Proteins MobC1 (164 AA) and MobA (410 AA) belong to the relaxase family (pfam05713) of enzymes and are likely to be involved in DNA strand separation and nicking of the nic site of the oriT sequences, respectively (van Kranenburg and de Vos, 1998). Both proteins are $98 \%$ identical to their homologs from lactococcal plasmids pNZ4000 (van Kranenburg et al., 2000) and pCI528 (Lucey et al., 1993). Proteins MobB (207 AA) and MobC2 (200 AA) share 89 and 99\% identity with MobB and MobC from pNZ4000, respectively. These proteins are also thought to be involved in plasmid mobilization but their role is unclear (van Kranenburg et al., 2000), as no canonical mobilization domains are found in their sequence. The BLAST analysis showed that the $\mathrm{mobC}_{2}$ gene is recurrent among the Bacillus, Streptococcus, and Enterococcus genera, whereas it returned a single hit (pNZ4000) from the Lactococcus genus. This suggests that $m o b C_{2}$ has been probably acquired during a recent horizontal gene transfer. Finally, genes encoding mobilization proteins were also found on pAF12 $\left(m o b C D_{1} D_{2}\right)$ and on pAF07 (mobCA; Figure 2; Supplementary Material Tables 3-4, available online at http://www.journalofdairyscience.org/).

\section{Lactococcus lactis DPC3758 Harbors Various Stress Response Determinants That May Be Used As Food-Grade Selection Markers}

Lactococcus lactis DPC3758 plasmids were found to contain several stress-response genes conferring immunity/resistance to the bacteriocins nisin and lacticin 481, and to the heavy metals cadmium and copper. In addition to their primary role of enhancing the robustness and survival capabilities of the host, these genes also represent 4 well-documented markers of selection for transfer of plasmids in lactococci. As indigenous genotypes, they are considered food grade and are, therefore, acceptable for use in dairy cultures desig- nated for human consumption. All have been previously exploited to produce phage-resistant derivatives of $L$. lactis cultures or to construct food-grade cloning vectors (or both) that are central to future programs of starter improvement (Khunajakr et al., 1999; Trotter et al., 2001; Coffey and Ross, 2002; Liu et al., 2002, 2005; Mills et al., 2002).

In L. lactis DPC3758, nisin resistance is afforded by a 956-bp gene present on pAF65 that is $99 \%$ identical to the resistance gene $n s r$ present on the $60-\mathrm{kb}$ conjugative plasmid pNP40 from L. lactis DRC3 (O'Driscoll et al., 2006). Nisin resistance protein (NSR; 318 AA) contains an N-terminal membrane-spanning domain and a C-terminal processing peptidase domain (cd06567) typical of serine proteases. A recent study showed that lactococcal NSR confers the host with nisin resistance by using a novel mechanism involving proteolytic removal of the C-terminal tail of nisin. The peptidase/ protease domain of NSR has been suggested to reside on the extracellular side of the membrane, where it might contact and degrade nisin (Sun et al., 2009). Plasmid pAF65 also carries the classical immunity determinants lctFEG, conferring resistance to lacticin 481, which are generally organized within an operon also containing genes (lctAMT) involved in lacticin 481 biosynthesis and export (Rince et al., 1994). However, these latter genes are missing in L. lactis DPC3758. The proteins encoded by lctFEG genes have hydrophobicity profiles and sequence similarities that strongly suggest an $\mathrm{ABC}$ transporter protecting the lacticin 481 producer strain from its own lantibiotic (Rincé et al., 1997). A copper resistance operon, lcoRSABC, (Figure 2; Supplementary Material Table 12, available online at http://www. journalofdairyscience.org/) identical to corresponding homologs on lactococcal plasmids pND306 (Khunajakr et al., 1999; Liu et al., 2002) and pSK11P (Siezen et al., 2005) are also present on pAF65. As observed in pSK11P, the operon is flanked by 2 copies of IS-LL6 transposase A to form a putative composite transposon (Siezen et al., 2005). The operon confers copper resistance in L. lactis by reducing the intracellular accumulation of copper ions via a 2-component regulatory system composed of a DNA-binding response regulator (LcoR, $223 \mathrm{AA}$ ) and a signal transduction histidine kinase (LcoS, 465 AA), which regulate the copperinducible transcription of downstream genes $l c o A B C$. All LcoABC proteins are required for copper resistance, but none of them contain any putative copper-binding motifs. This suggests that LcoABC proteins play an indirect role in the cell to achieve copper homeostasis (Khunajakr et al., 1999; Liu et al., 2002). Protein LcoA (269 AA) is a putative prolipoprotein diacylglyceryl transferase (cl00478) and contains 7 membranespanning hydrophobic regions, which suggests an in- 

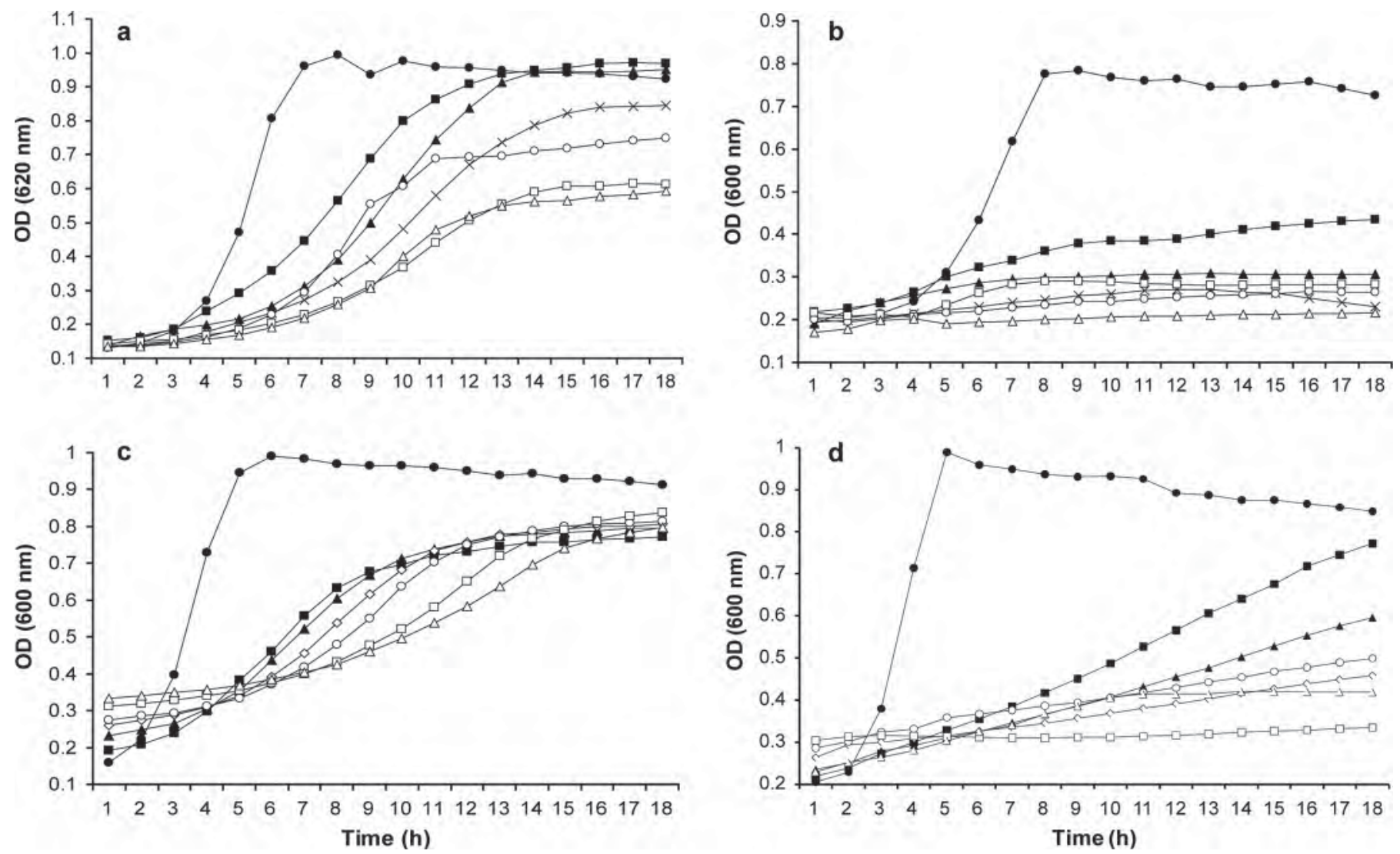

Figure 4. Functional analyses of the cadmium (a, b) and copper (c, d) resistance operons in Lactococcus lactis DPC3758 compared with the sensitive strain L. lactis MG1363. Growth curves, as measured by the increase in optical density (OD) at $600 \mathrm{~nm}$, of L. lactis DPC3758 (a) and MG1363 (b) in media containing $0(\bullet), 0.05(\mathbf{\square}), 0.1(\mathbf{\Delta}), 0.15(\mathrm{x}), 0.2(\bigcirc), 0.25(\square)$ and $0.3 \mathrm{~m} M(\Delta)$ cadmium chloride. Growth curves of $L$. lactis DPC3758 (c) and MG1363 (d) in media containing $0(\bullet), 1(\mathbf{\square}), 2(\mathbf{\Delta}), 3(\diamond), 4(\bigcirc), 5(\square)$, and $6 \mathrm{~m} M(\Delta)$ cupric sulfate.

tramembrane location. Protein LcoB (451 AA) is an abundantly secreted protein of L. lactis but its function remains unknown. The C-terminal cysteine, histidinedependent amidohydrolase/peptidase (CHAP) domain (PF05257) of LcoB would suggest a putative role as amidase involved in peptidoglycan metabolism (Siezen et al., 2005). It is probably attached to the cell membrane through the N-terminal spectrin repeat (cd00176) domain, which might also provide binding sites to favor the assembly of large multi-protein regulatory or resistance complexes (Djinovic-Carugo et al., 2002). Protein LcoC (464 AA) is highly homologous to multicopper oxidases (COG2132) and contains a lipoprotein signal motif, which suggests a likely translocation across the membrane to the outside of the cell to be covalently anchored by LcoA to membrane lipids (Siezen et al., 2005). Analysis of growth in the presence of copper showed the functionality of the lco operon in L. lactis DPC3758 (Figure 4c and 4d). Although the growth of L. lactis MG1363 was strongly inhibited by $\mathrm{CuSO}_{4}$ concentrations above $1 \mathrm{~m} M$, L. lactis DPC3758 was able to grow relatively well even at copper concentrations of $6 \mathrm{~m} M$.

Resistance to cadmium in L. lactis DPC3758 is conferred by 2 overlapping genes present on pAF14 (Figure 2; Supplementary Material Table 2, available online at http://www.journalofdairyscience.org/), which are $99 \%$ identical to the cadmium resistance cassette cadAC present in lactococcal plasmids pAH82 (O' Sullivan et al., 2001), pGdh442 (Tanous et al., 2007), and pNP40 (O'Driscoll et al., 2006), and in several other grampositive bacteria (Schirawski et al., 2002). These genes are organized as an operon, and their transcription is cadmium dependent in vivo. The complete cassette has been shown to confer cadmium and zinc resistance to both Streptococcus thermophilus and L. lactis, but expression of cadA alone is sufficient to give resistance (Schirawski et al., 2002). Protein CadA (705 AA) is a cation-translocating P-type ATPase (COG2217, COG4087) that allows efflux of cadmium, thus resulting in reduced accumulation of the toxic cation. Protein CadC (119 AA) is highly similar to ArsR-type regula- 
tory proteins and has been shown to act as a repressor of the cadmium-dependent expression of $\operatorname{cadA}$ by binding to its own promoter region, an interaction that is lost in the presence of cadmium (Yoon et al., 1991; Schirawski et al., 2002). The functionality of the $c a d A C$ cassette of pAF14 was tested by comparing the growth of DPC3758 to that of the $\mathrm{Cd}^{\mathrm{S}}$ strain L. lactis MG1363, in the presence of increasing concentrations of $\mathrm{CdCl}_{2}$ (Figure 4a and 4b). Lactococcus lactis DPC3758 was able to tolerate $\mathrm{CdCl}_{2}$ concentrations of up to $0.3 \mathrm{mM}$, whereas L. lactis MG1363 was inhibited by concentrations as low as $0.05 \mathrm{~m} M$.

In L. lactis DPC3758, 3 markers (nisin, lacticin 481, and copper resistance) are contained on a plasmid (pAF65) also carrying conjugative proteins (Tra3) and a phage-resistance mechanism (R/M-I). This represents the ideal situation as it overcomes the known difficulties encountered in delivering natural anti-phage systems to industrial strains (Forde and Fitzgerald, 1999; Coffey and Ross, 2002; Mills et al., 2006).

\section{The R/M Systems of L. lactis DPC3758 are Transmissible and Their Stacking Increases the Phage Resistance of the Host}

Lactococcus lactis DPC3758 plasmids are of significant interest for programs of starter improvement, as the presence of multiple transfer regions and food-grade selectable markers would facilitate their delivery to industrial strains. Therefore, a series of conjugation experiments were undertaken to evaluate the transmissible nature of these plasmids. In agreement with previous reports (O' Sullivan et al., 2001; Trotter et al., 2001), cadmium resistance proved to be a very effective selectable marker for plasmid transfer to the chosen recipient, L. lactis MG1614. Analysis of the plasmid profiles of 20 random transconjugants showed that all had acquired a plasmid of approximately $14 \mathrm{~kb}$, similar in size to pAF14, which contains the cadmium determinants. Interestingly, only few transconjugants contained pAF14 on its own, whereas the majority had acquired 1 or more additional plasmids, giving rise to a total of 7 major plasmid patterns (Figure 5a). Based on plasmid profile analysis, it was deduced that the transconjugants Tc5, Tc6, and Tc7 harbored different combinations of the 3 L. lactis DPC3758 R/M systems, a finding that was confirmed using primers specific to each of these mechanisms (Figure 5b). This allowed the evaluation of the restriction efficiency afforded by each $\mathrm{R} / \mathrm{M}$ system against phages $\mathrm{c} 2$ and 712 , representatives of the predominant phage types found in dairy industry, in a plasmid-free background (Figure $5 \mathrm{c}$ ).

Systems R/M-IIa and R/M-IIb were shown to restrict the 936 phages more efficiently than the $\mathrm{c} 2$ phages, presumably due to the larger genome and correspondingly higher number of recognition sites in the former. The phage EOP is known to decrease exponentially as the number of sites in the viral genome increases (Forde and Fitzgerald, 1999). The presence of R/MIIa in MG1614-Tc6 resulted in a 2-log decrease of the EOP of phage 712 , whereas it proved almost ineffective against phage $\mathrm{c} 2$. These results are in agreement with the restriction efficiency reported for the LlaCI system, which is homologous to R/M-IIa and was shown to confer $L$. lactis strains with decreased sensitivity to phages of the 936 or P335 but not to the c2 species (Madsen and Josephsen, 1998a). The inefficacy against these latter phages was associated with the lack of HindIII/LlaCI restriction sites in their genomes (Madsen and Josephsen, 1998a). Superimposition of R/M-IIb on $\mathrm{R} / \mathrm{M}-\mathrm{IIa}$ (MG1614-Tc7) resulted in additive restriction of phage 712 by causing a further 2.5-log EOP reduction and increasing the efficiency of restriction to close to $10^{-5}$. Conversely, R/M-IIb stacking did not improve host resistance against phage $\mathrm{c} 2$. These results are less than expected from the additive restriction afforded by a LlaDII homolog, as this mechanism was reported to reduce by 2 - and 4 -fold the EOP of phage species c2 and 936, respectively (Madsen and Josephsen, 1998b).

Whereas the chromosomally-encoded type I R/M system of L. lactis IL1403 is known to restrict c2-type phages with low efficiency (2 logs; Schouler et al., 1998b), its homolog in L. lactis DPC3758 (R/M-I) was found to possess a broader and greater restriction ability. Indeed, the superimposition of R/M-I on the low-efficiency R/M-IIb system (MG1614-Tc5) provided the L. lactis MG1614 host with complete protection against both phages $\mathrm{c} 2$ and 712 . These results confirm that the novel TRD of R/M-I HsdS compared with that of the L. lactis IL1403 homolog is able to provide the system with altered specificity and restriction activity. The HsdS subunits determine the target sequence specificity of type I R/M systems via both TRD, each one responsible for recognizing half of a bipartite target site (Murray, 2000). It is, therefore, obvious that the acquisition of a different TRD, which may occur via recombination of $h s d S$ genes as observed in pAH90 (O'Sullivan et al., 2000), is able to generate a new R/M specificity.

Results of the conjugation study reveal that most of L. lactis DPC3758 plasmids, including those containing the $\mathrm{R} / \mathrm{M}$ systems, are self-conjugative and may be comobilized alongside other plasmids even in the absence of specific selection. This feature has important commercial implications, as it may be exploited to develop industrial cultures with improved phage resistance through targeted delivery of anti-phage mechanisms. Theoretically, all $\mathrm{R} / \mathrm{M}$ systems of L. lactis $\mathrm{DPC} 3758$ 


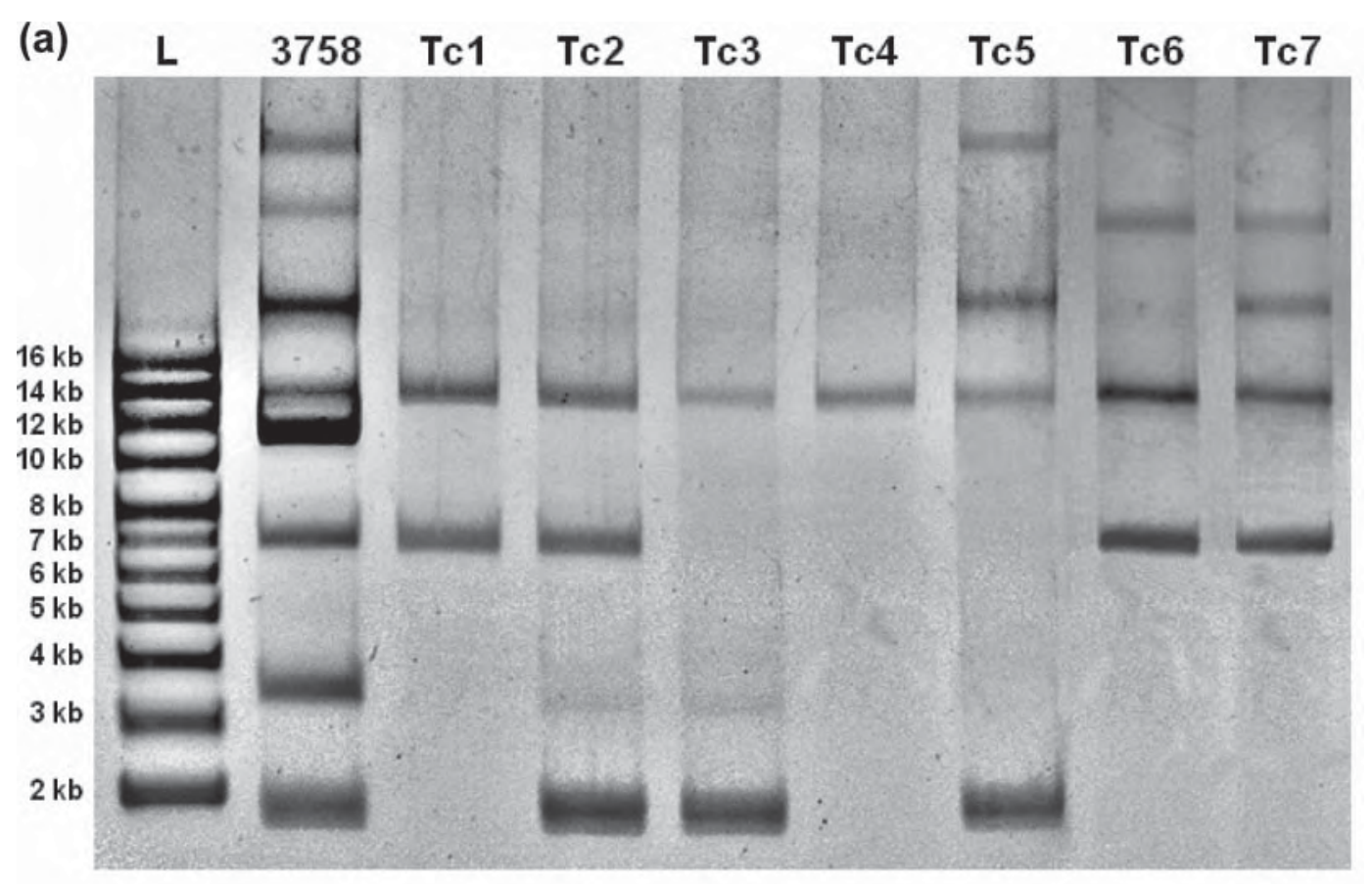

(b)

R/M-I

R/M-IIa

R/M-IIb

(c)

\begin{tabular}{lcccc}
\hline & MG1614 & TC5 & Tc6 & Tc7 \\
\hline EOPs & & & & \\
ФC2 & 1 & 0 & 0.33 & 0.21 \\
$\Phi 712$ & 1 & 0 & $3.7 \times 10^{-2}$ & $8.3 \times 10^{-4}$ \\
\hline
\end{tabular}

Figure 5. (a) Plasmid profiles of the plasmid donor strain Lactococcus lactis DPC3758 and of L. lactis MG1614 transconjugants (Tc1 to Tc7), obtained by using cadmium resistance as selectable marker. (b) PCR detection of restriction/modification (R/M) systems in selected transconjugants. (c) Efficiency of plaquing (EOP) of phages c2 and 712 on selected transconjugants harboring different combinations of R/M systems.

may be sequentially or concomitantly transferred to phage-sensitive industrial starters, thus providing the host with enhanced protection against phage attack as a result of the additive resistance mediated by the stacking of 3 different restriction specificities. Such strategies are generally limited by the lack of a suitable marker on the plasmid, which would facilitate the selection of transconjugants harboring the newly acquired trait. This limitation should not affect the delivery of L. lactis DPC3758 plasmids, as they encode 4 phenotypes with well-documented application as food-grade selectable markers (Trotter et al., 2001; Liu et al., 2002; Mills et al., 2002).

\section{CONCLUSIONS}

This study confirmed the value of the approach targeting natural $L$. lactis isolates from raw milk cheeses for genetic traits with potential application in programs of dairy starter improvement. Sequencing and functional analysis of the 8-plasmid complement of L. lactis DPC3758 revealed a wealth of genetic traits encoding multiple anti-phage systems, resistance genes/selectable markers, and functional conjugative/mobilization regions. The identification of such natural plasmids is of tremendous benefit for the successful outcome of any program of starter improvement, as the association of 
food-grade selectable markers and mobilization functions on many of these plasmids will facilitate their exploitation to obtain lactococcal industrial strains with enhanced phage protection and robustness. Lactococcus lactis DPC3758 plasmids also provide another example of the major role played by these genetic elements in contributing to host fitness and preservation within its ecological niche. Raw milk is likely to prove an extremely challenging habitat to live in due to the presence of a large and heterogeneous microflora and, putatively, of related phages. Harboring multiple conjugative plasmids containing 3 separate $\mathrm{R} / \mathrm{M}$ systems and various stress resistance determinants clearly provides $L$. lactis DPC3758 with a competitive advantage to survive in this environment. The observation that 6 out of 8 plasmids carry mobilization functions is suggestive of their likely acquisition by horizontal transfer from organisms occupying the same habitat, and also indicative of the high level of genome plasticity of the strain.

Our study provides the gene knowledge base to exploit single plasmids from L. lactis DPC3758, although the whole strain might be safely used as a component of novel starter formulations. Lactococcus lactis DPC3758 has been indeed genotyped as a cremoris strain, which is highly desirable in the manufacture of Cheddar and other cheese varieties (Salama et al., 1995; Delgado and Mayo, 2004), and also does not contain any undesired virulence or antibiotic resistance genes. The wealth of potentially useful genetic traits found in L. lactis DPC3758 plasmids also reaffirms the importance of ongoing screening aimed at isolating and characterizing new lactococcal strains from natural nondairy ecosystems. If pursued, this strategy will provide a whole new range of natural starters or properties to develop novel or improved starter formulations with enhanced robustness and long-term efficiency.

\section{ACKNOWLEDGMENTS}

This research was funded by Irish Dairy Levy. V. Fallico received a grant from Irish Research Council for Science, Engineering and Technology (IRCSET, Dublin, Ireland) under the Embark initiative.

\section{REFERENCES}

Altschul, S., T. Madden, A. Schaffer, J. H. Zhang, Z. Zhang, W. Miller, and D. Lipman. 1998. Gapped BLAST and PSI-BLAST: A new generation of protein database search programs. FASEB J. 12:A1326.

Ballesteros, C., J. M. Poveda, M. A. González-Viñas, and L. Cabezas. 2006. Microbiological, biochemical and sensory characteristics of artisanal and industrial Manchego cheeses. Food Contr. $17: 249-255$.
Chopin, A., M.-C. Chopin, A. Moillo-Batt, and P. Langella. 1984. Two plasmid-determined restriction and modification systems in Streptococcus lactis. Plasmid 11:260-263.

Coffey, A., and R. P. Ross. 2002. Bacteriophage-resistance systems in dairy starter strains: Molecular analysis to application. Antonie van Leeuwenhoek 82:303-321.

Cogan, T. M., M. Barbosa, E. Beuvier, B. Bianchi-Salvadori, P. S. Cocconcelli, I. Fernandes, J. Gomez, R. Gomez, G. Kalantzopoulos, A. Ledda, M. Medina, M. C. Rea, and E. Rodriquez. 1997. Characterization of the lactic acid bacteria in artisanal dairy products. J. Dairy Res. 64:409-421.

Delcher, A. L., D. Harmon, S. Kasif, O. White, and S. L. Salzberg. 1999. Improved microbial gene identification with GLIMMER. Nucleic Acids Res. 27:4636-4641.

Delgado, S., and B. Mayo. 2004. Phenotypic and genetic diversity of Lactococcus lactis and Enterococcus spp. strains isolated from Northern Spain starter-free farmhouse cheeses. Int. J. Food Microbiol. 90:309-319.

Djinovic-Carugo, K., M. Gautel, J. Ylänne, and P. Young. 2002. The spectrin repeat: A structural platform for cytoskeletal protein assemblies. FEBS Lett. 513:119-123.

Dougherty, B. A., C. Hill, J. F. Weidman, D. R. Richardson, J. C. Venter, and R. P. Ross. 1998. Sequence and analysis of the $60 \mathrm{~kb}$ conjugative, bacteriocin-producing plasmid pMRC01 from Lactococcus lactis DPC3147. Mol. Microbiol. 29:1029-1038.

Finn, R. D., J. Mistry, J. Tate, P. C. Coggill, A. Heger, J. E. Pollington, O. L. Gavin, P. Gunasekaran, G. Ceric, K. Forslund, L. Holm, E. L. L. Sonnhammer, S. R. Eddy, and A. Bateman. 2010. The Pfam protein families database. Nucleic Acids Res. 38:D211D222.

Forde, A., and G. F. Fitzgerald. 1999. Bacteriophage defence systems in lactic acid bacteria. Antonie van Leeuwenhoek 76:89-113.

Ito, Y., Y. Kawai, K. Arakawa, Y. Honme, T. Sasaki, and T. Saito. 2009. Conjugative plasmid from Lactobacillus gasseri LA39 that carries genes for production of and immunity to the circular bacteriocin gassericin A. Appl. Environ. Microbiol. 75:6340-6351.

Jarvis, A. W., G. F. Fitzgerald, M. Mata, A. Mercenier, H. Neve, I. B. Powell, C. Ronda, M. Saxelin, and M. Teuber. 1991. Species and type phages of lactococcal bacteriophages. Intervirology 32:2-9.

Josephsen, J., and T. Klaenhammer. 1990. Stacking of 3 different restriction and modification systems in Lactococcus lactis by cotransformation. Plasmid 23:71-75.

Khunajakr, N., C.-Q. Liu, P. Charoenchai, and N. W. Dunn. 1999 A plasmid-encoded two-component regulatory system involved in copper-inducible transcription in Lactococcus lactis. Gene 229:229-235.

Leelawatcharamas, V., L. G. Chia, P. Charoenchai, N. Kunajakr, C.Q. Liu, and N. W. Dunn. 1997. Plasmid-encoded copper resistance in Lactococcus lactis. Biotechnol. Lett. 19:639-643.

Lillehaug, D. 1997. An improved plaque assay for poor plaque-producing temperate lactococcal bacteriophages. J. Appl. Microbiol. 83:85-90.

Liu, C.-Q., P. Charoechai, N. Khunajakr, Y.-M. Deng, Widodo, and N. W. Dunn. 2002. Genetic and transcriptional analysis of a novel plasmid-encoded copper resistance operon from Lactococcus lactis. Gene 297:241-247.

Liu, C.-Q., P. Su, N. Khunajakr, Y.-M. Deng, S. Sumual, W. S. Kim, J. E. Tandianus, and N. W. Dunn. 2005. Development of foodgrade cloning and expression vectors for Lactococcus lactis. J. Appl. Microbiol. 98:127-135.

Lucey, M., C. Daly, and G. Fitzgerald. 1993. Analysis of a region from the bacteriophage resistance plasmid pCI528 involved in its conjugative mobilization between Lactococcus strains. J. Bacteriol. 175:6002-6009.

Madsen, A., and J. Josephsen. 1998a. Characterization of $\mathrm{LlaCl}$, a new restriction-modification system from Lactococcus lactis subsp. cremoris W15. Biol. Chem. 379:443-449.

Madsen, A., and J. Josephsen. 1998b. Cloning and characterization of the lactococcal plasmid-encoded type II restriction/modification system, LlaDII. Appl. Environ. Microbiol. 64:2424-2431. 
Marchler-Bauer, A., J. B. Anderson, F. Chitsaz, M. K. Derbyshire, C. DeWeese-Scott, J. H. Fong, L. Y. Geer, R. C. Geer, N. R. Gonzales, M. Gwadz, S. He, D. I. Hurwitz, J. D. Jackson, Z. Ke, C. J. Lanczycki, C. A. Liebert, C. Liu, F. Lu, S. Lu, G. H. Marchler, M. Mullokandov, J. S. Song, A. Tasneem, N. Thanki, R. A. Yamashita, D. Zhang, N. Zhang, and S. H. Bryant. 2009. CDD: Specific functional annotation with the Conserved Domain Database. Nucleic Acids Res. 37:D205-D210.

McKay, L. L., and K. A. Baldwin. 1984. Conjugative 40-megadalton plasmid in Streptococcus lactis subsp. diacetylactis DRC3 is associated with resistance to nisin and bacteriophage. Appl. Environ. Microbiol. 47:68-74.

Mills, S., A. Coffey, L. O'Sullivan, D. Stokes, C. Hill, G. F. Fitzgerald, and R. P. Ross. 2002. Use of lacticin 481 to facilitate delivery of the bacteriophage resistance plasmid, pCBG104 to cheese starters. J. Appl. Microbiol. 92:238-246.

Mills, S., O. E. McAuliffe, A. Coffey, G. F. Fitzgerald, and R. P. Ross. 2006. Plasmids of lactococci-Genetic accessories or genetic necessities? FEMS Microbiol. Rev. 30:243-273.

Mruk, I., M. Cichowicz, and T. Kaczorowski. 2003. Characterization of the LlaCI methyltransferase from Lactococcus lactis subsp. cremoris W15 provides new insights into the biology of type II restriction-modification systems. Microbiology 149:3331-3341.

Murray, N. E. 2000. Type I restriction systems: Sophisticated molecular machines (a legacy of Bertani and Weigle). Microbiol. Mol. Biol. Rev. 64:412-434.

Nomura, M., M. Kobayashi, T. Narita, H. Kimoto-Nira, and T. Okamoto. 2006. Phenotypic and molecular characterization of Lactococcus lactis from milk and plants. J. Appl. Microbiol. 101:396405.

Notredame, C., D. G. Higgins, and J. Heringa. 2000. T-Coffee: A novel method for fast and accurate multiple sequence alignment. J. Mol. Biol. 302:205-217.

O'Driscoll, J., F. Glynn, G. F. Fitzgerald, and D. van Sinderen. 2006. Sequence analysis of the lactococcal plasmid pNP40: A mobile replicon for coping with environmental hazards. J. Bacteriol. 188:6629-6639.

O'Sullivan, D., A. Coffey, G. F. Fitzgerald, C. Hill, and R. P. Ross. 1998. Design of a phage-insensitive lactococcal dairy starter via sequential transfer of naturally occurring conjugative plasmids. Appl. Environ. Microbiol. 64:4618-4622.

O' Sullivan, D., R. P. Ross, D. P. Twomey, G. F. Fitzgerald, C. Hill, and A. Coffey. 2001. Naturally occurring lactococcal plasmid pAH90 links bacteriophage resistance and mobility functions to a food-grade selectable marker. Appl. Environ. Microbiol. 67:929937.

O'Sullivan, D., D. P. Twomey, A. Coffey, C. Hill, G. F. Fitzgerald, and R. P. Ross. 2000. Novel type I restriction specificities through domain shuffling of HsdS subunits in Lactococcus lactis. Mol. Microbiol. 36:866-875.

O'Sullivan, D. J., and T. R. Klaenhammer. 1993. Rapid mini-prep isolation of high-quality plasmid DNA from Lactococcus and Lactobacillus spp. Appl. Environ. Microbiol. 59:2730-2733.

Rince, A., A. Dufour, S. Le Pogam, D. Thuault, C. M. Bourgeois, and J. P. Le Pennec. 1994. Cloning, expression, and nucleotide sequence of genes involved in production of lactococcin DR, a bacteriocin from Lactococcus lactis subsp. lactis. Appl. Environ. Microbiol. 60:1652-1657.

Rincé, A., A. Dufour, P. Uguen, J.-P. Le Pennec, and D. Haras. 1997. Characterization of the lacticin 481 operon: The Lactococcus lactis genes $l c t F$, lctE, and lct $G$ encode a putative $\mathrm{ABC}$ transporter involved in bacteriocin immunity. Appl. Environ. Microbiol. 63:4252-4260.

Rutherford, K., J. Parkhill, J. Crook, T. Horsnell, P. Rice, M.-A. Rajandream, and B. Barrell. 2000. Artemis: Sequence visualization and annotation. Bioinformatics 16:944-945.
Ryan, M. P., M. C. Rea, C. Hill, and R. P. Ross. 1996. An application in cheddar cheese manufacture for a strain of Lactococcus lactis producing a novel broad-spectrum bacteriocin, lacticin 3147. Appl. Environ. Microbiol. 62:612-619.

Salama, M. S., T. Musafija-Jeknic, W. E. Sandine, and S. J. Giovannoni. 1995. An ecological study of lactic acid bacteria: Isolation of new strains of Lactococcus including Lactococcus lactis subspecies cremoris. J. Dairy Sci. 78:1004-1017.

Sanders, M. E., and T. R. Klaenhammer. 1983. Characterization of phage-sensitive mutants from a phage-insensitive strain of Streptococcus lactis: Evidence for a plasmid determinant that prevents phage adsorption. Appl. Environ. Microbiol. 46:1125-1133.

Schirawski, J., W. Hagens, G. F. Fitzgerald, and D. van Sinderen. 2002. Molecular characterization of cadmium resistance in Streptococcus thermophilus strain 4134: An example of lateral gene transfer. Appl. Environ. Microbiol. 68:5508-5516.

Schouler, C., F. Clier, A. L. Lerayer, S. D. Ehrlich, and M.-C. Chopin. 1998a. A type IC restriction-modification system in Lactococcus lactis. J. Bacteriol. 180:407-411.

Schouler, C., M. Gautier, S. D. Ehrlich, and M.-C. Chopin. 1998b. Combinational variation of restriction modification specificities in Lactococcus lactis. Mol. Microbiol. 28:169-178.

Siezen, R. J., B. Renckens, I. van Swam, S. Peters, R. van Kranenburg, M. Kleerebezem, and W. M. de Vos. 2005. Complete sequences of four plasmids of Lactococcus lactis ssp. cremoris SK11 reveal extensive adaptation to the dairy environment. Appl. Environ. Microbiol. 71:8371-8382.

Sun, Z., J. Zhong, X. Liang, J. Liu, X. Chen, and L. Huan. 2009. Novel mechanism for nisin resistance via proteolytic degradation of nisin by the nisin resistance protein NSR. Antimicrob. Agents Chemother. 53:1964-1973.

Tanous, C., E. Chambellon, and M. Yvon. 2007. Sequence analysis of the mobilizable lactococcal plasmid pGdh442 encoding glutamate dehydrogenase activity. Microbiology 153:1664-1675.

Terzaghi, B. E. 1988. Improved medium for lactic streptococci and their bacteriophages. Citation Classic Commentaries, Current Contents/Life Sci. 24:24. Accessed Apr. 3, 2012. http://garfield. library.upenn.edu/classics1988/A1988N613100001.pdf.

Trotter, M., S. Mills, R. P. Ross, G. F. Fitzgerald, and A. Coffey. 2001 The use of cadmium resistance on the phage-resistance plasmid pNP40 facilitates selection for its horizontal transfer to industrial dairy starter lactococci. Lett. Appl. Microbiol. 33:409-414.

van Kranenburg, R., and W. M. de Vos. 1998. Characterization of multiple regions involved in replication and mobilization of plasmid pNZ4000 coding for exopolysaccharide production in Lactococcus lactis. J. Bacteriol. 180:5285-5290.

van Kranenburg, R., N. Golic, R. Bongers, R. J. Leer, W. M. de Vos, R. J. Siezen, and M. Kleerebezem. 2005. Functional analysis of three plasmids from Lactobacillus plantarum. Appl. Environ. Microbiol. 71:1223-1230.

van Kranenburg, R., M. Kleerebezem, and W. M. de Vos. 2000. Nucleotide sequence analysis of the lactococcal EPS plasmid pNZ4000. Plasmid 43:130-136.

Yoon, K. P.. T. K. Misra, and S. Silver. 1991. Regulation of the cadA cadmium resistance determinant of Staphylococcus aureus plasmid pI258. J. Bacteriol. 173:7643-7649.

Zdobnov, E. M., and R. Apweiler. 2001. InterProScan-An integration platform for the signature-recognition methods in InterPro. Bioinformatics 17:847-848.

Zhang, W., D. Yu, Z. Sun, X. Chen, Q. Bao, H. Meng, S. Hu, and H. Zhang. 2008. Complete nucleotide sequence of plasmid plca36 isolated from Lactobacillus casei Zhang. Plasmid 60:131-135.

Zhang, Z., S. Schwartz, L. Wagner, and W. Miller. 2000. A greedy algorithm for aligning DNA sequences. J. Comput. Biol. 7:203-214. 